REVIEW ARTICLE

\title{
Insecticide resistance in mosquitoes: Development, mechanisms and monitoring
}

\author{
S.H.P. Parakrama Karunaratne ${ }^{1, *}$, W.A. Priyanka P. De Silva ${ }^{1}$, Thilini Chathurika Weeraratne ${ }^{1}$ and \\ Sinnathamby Noble Surendran ${ }^{2}$
}

${ }^{1}$ Department of Zoology, Faculty of Science, University of Peradeniya, Peradeniya, Sri Lanka

${ }^{2}$ Department of Zoology, Faculty of Science, University of Jaffna, Jaffna, Sri Lanka

Received:20/05/2018; Accepted:16/07/2018

\begin{abstract}
Mosquito-borne diseases are of major public health concerns, mainly in tropical countries. Control of these diseases is primarily achieved through mosquito control. One of the major challenges encountered by mosquito control programmes is the development of resistance to insecticides by mosquitoes. Increased detoxifying activity through over expression of insect metabolic enzymes and altered target sites with decreased sensitivity to insecticides are the two major mechanisms of resistance. This review article presents our knowledge on development of insecticide resistance and the underlying biochemical and molecular mechanisms of resistance to major classes of insecticides. Techniques available to monitor resistance and to understand the underlying mechanisms are also discussed.
\end{abstract}

Keywords: mosquito control, insecticide resistance, resistance mechanisms, metabolic resistance, target-site insensitivity, monitoring insecticide resistance.

\section{INTRODUCTION}

Despite our longstanding struggle to control mosquito populations, mosquito-borne diseases believed to cause nearly one million deaths and over 700 million infections worldwide annually (Caraballo et al., 2014). Mosquitoes which act as major vectors of dangerous human diseases belong to three genera; Anopheles, Culex and Aedes. Anopheles are the vectors of malaria and there have been about 214 million cases of malaria resulting 438,000 deaths worldwide annually (WHO, 2016a). Nearly 1.1 billion people are at risk of contracting lymphatic filariasis (WHO, 2016b), which is transmitted by Culex quinquefasciatus and species of Anopheles and Mansonia. Culex tritaeniorhynchus is the major vector of Japanese encephalitis, which is found in tropical and sub-tropical countries (CDC, 2016). Aedes aegypti and Aedes albopictus mosquitoes are mainly responsible for transmitting dengue and dengue hemorrhagic fever, yellow fever, and chickungunya (Weaver and Reisen, 2010; WHO, 2016c). It is estimated that dengue infections affect nearly 2.4 million individuals annually (WHO, 2016c). The recent Zika virus (ZIKV) transmission by Ae. aegypti in the Americas has alerted health authorities globally to implement measures to control its transmission (Lazear et al., 2016).

In the absence of specific drugs and licensed vaccines against many mosquito-borne diseases, mosquito control has become the major strategy to reduce or prevent disease transmission. Insecticides play the most important role in controlling mosquito vectors of diseases worldwide. Although, six classes of insecticides viz. organochlorines, organophosphates, carbamates, pyrethroids, pyrroles, and phenyl pyrazoles are currently used in mosquito control programmes worldwide (WHO, 2016d), resistance has been extensively reported against the first four groups. Organochlorine DDT was the first synthetic insecticide introduced for mosquito control in 1946 and because of its success, WHO assembly proposed the global eradication of malaria, by the use of residual house-spraying of DDT in1955. However, in 1976 WHO officially reverted its proposal from malaria eradication to malaria control. The major reason for the policy change was the appearance of DDT resistance in a broad range of mosquito vectors (Bradley, 1998). Resistance continued to be a key problem even against the subsequently introduced organophosphorus, carbamate and pyrethroid insecticides. However, malaria incidence has reduced by $50 \%$ since 2000 , with $80 \%$ of the reduction attributed to the use of insecticides in the form of indoor residual spraying (IRS), insecticide-treated nets (ITNs) and long-lasting insecticide-treated bed nets (LLITS) (WHO, 2012), which are under the threat of resistance (Balabanidou et al., 2016). Understanding the mechanisms of insecticide resistance for a proper management of insecticides is a key step in avoiding or delaying the resistance development phenomenon.

\section{DEVELOPMENT OF INSECTICIDE RESISTANCE}

Insecticide resistance is considered to be an important evolutionary phenomenon (Naqqash et al., 2016) apart from its implications in insect vector control worldwide. Development of insecticide resistance is a complex process depending directly on genetic, physiological, behavioural and ecological factors and indirectly on the volume and frequency of applications of insecticides (Zhu et al., 2016). Many control programs were operationally switched from blanket spraying to focal use to delay the development of resistance (Hemingway and Ranson, 2000). Nevertheless, 
mosquitoes have all the characteristics suited for a rapid selection of resistance including short life cycles with abundant progeny and other inherent characteristics. Insecticide resistance has been associated with a preadaptive phenomenon that explains existence of rare individuals who carry one or more resistant alleles allowing them to increase in number following the subsequent application of insecticides (Liu, 2015).

Research on insecticide resistance, molecular mechanisms of resistance and rational resistance management is of paramount importance to control the development and spread of resistance in vector populations. Target site for organophosphates and carbamates is insect acetylcholinesterases. For pyrethroids and a group of organochlorines (DDT + its analogues), the target site is $\mathrm{Na}^{+}$channel regulatory proteins of the nerve membrane. For the rest of the organochlorines (cyclodienes), it is $\gamma$ aminobutyric acid (GABA) receptors. Three major types of resistance mechanisms namely; metabolic resistance (changes in insect enzyme systems leading to rapid detoxification or sequestration of insecticides), targetsite resistance (alterations of the insecticide target sites preventing their binding to insecticides) and cuticular resistance (reduced penetration of insecticides due to a thickening or change in chemical composition of the cuticle) have been described (Karunaratne, 1998; Hemingway et al., 2004).

Although "increased rates of excretion" is also considered as a resistance mechanism by some authors, involvement of such a mechanism for resistance development has not been supported significantly in the literature. Behavioural changes developed to avoid or minimize the contact with and thereby reduce the uptake of insecticides may also considered as a mechanism of resistance. A change of behaviour from indoor resting to outdoor resting has been observed in malaria vectors $A n$. minimus and An. gambiae as a response to indoor spraying of insecticides (Bang, 1985; Reddy et al., 2011).

\section{MECHANISMS OF INSECTICIDE RESISTANCE}

\section{Increased detoxification by metabolic enzymes}

High genetic diversity has caused broad substrate specificity in insect metabolic enzymes and therefore the contribution of an enzyme for resistance development can vary significantly even against two closely related insecticides. Metabolic enzyme genes have a greater plasticity than insecticide target site genes and the increased metabolic capacity is usually achieved by increased activity of esterases (also known as carboxylesterases), glutathione S-transferases (GSTs) or monooxygenases (also known as oxidases or cytochrome $\mathrm{P}^{450} \mathrm{~s}$ ). Increased enzyme activity can be brought about by gene amplification, increased upregulation, coding sequence mutations or by a combination of these mechanisms. Basically, esterases can provide resistance to organophosphates, carbamates and pyrethroids which are rich with ester-bonds. GSTs can mediate resistance to organochlorines, organophosphates and pyrethroids, and $\mathrm{P}^{450} \mathrm{~s}$ act against all classes of insecticides (Li et al., 2007). Isolation and characterization of candidate genes/gene families which are over-expressed and/or with increased catalytic center activities in resistant vector populations have been carried out to varying degrees.

\section{Esterases}

The esterase-based resistance mechanism has been studied most extensively at the biochemical and molecular level in $C x$ quinquefasciatus mosquitoes. Broad-spectrum organophosphate resistance is conferred by increased quantities of esterases in more than $80 \%$ of resistant Culex worldwide. Esterases act by rapid binding and slow turning over the insecticide. They sequester rather than rapidly metabolize the insecticide (Karunaratne et al., 1993; 1995). It was found that gene amplification was responsible for the increased production and the resistant insects have up to 80 copies of the gene. Electron microscopic studies, using mosquito tissues and the antiserum raised against purified esterases revealed that increased esterase production in resistant mosquitoes occur in mosquito mid-gut and sub-cuticular layer, which are the main entry points for insecticides to mosquito body. Further studies suggested that elevated esterase activity in the gut cells of insecticide resistant, but not susceptible, mosquitoes affects the development of Wuchereria bancrofti larvae, the filarial parasite, in infected mosquitoes. Filarial worm infection of mosquitoes causes significant damage to the mosquito host, and high microfilaria infections result in mosquito death. The predominance of the elevated esterase-based resistance mechanism in field populations of $C x$ quinquefasciatus may therefore be influenced by the dual roles of insecticide detoxication and reduction of microfilarial burdens (McCarroll et al., 2000).

In $C x$ quinquefasciatus the most common elevated phenotype involves two enzymes, est $\alpha 2^{1}$ and est $\beta 2^{1}\left(\mathrm{~A}_{2}\right.$ and $\mathrm{B}_{2}$ on an earlier classification). The classification of these esterases is based on their preferences for $\alpha$-or $\beta$-naphthyl acetate, their mobility on native poly acrylamide gels, and their nucleotide sequence. Smaller numbers of $C x$ quinquefasciatus populations have elevated est $\beta^{1}$ alone, elevated est $\alpha^{1}$ alone or co-elevated est $\beta^{1}$ and est $\alpha^{3}$ (Hemingway and Karunaratne, 1998). Cx tritaeniorhyncus has a single amplified Ctrestblgene (Karunaratne et al., 1998). Elevated levels of esterases may not always be the result of gene amplification. The expression of est $\alpha 1$ in $C x$ pipiens from southern France was thought to be increased due to changes in an unidentified regulatory element rather than underlying amplification of the est $\alpha$ gene (Gullemaud et al., 1997). Expression of amplified esterase genes can also vary. Four-fold more est $\alpha 2^{1}$ than est $\beta 2^{1}$ was present in resistant $C x$ quinquefasciatus, although the genes were present in a 1:1 ratio. This difference in expression is reflected at the protein and mRNA level (Paton et al., 2000). In CX tarsalis, two resistance mechanisms co-exist: one involving elevated sequestering esterases, the other involving non-elevated metabolically active esterases (Ziegler et al., 1987). In contrast to the situation in Culex, a number of Anopheles species have a non-elevated esterase mechanism that confers resistance, specifically to malathion, through increased rates of metabolism 
(Hemingway, 1985; Karunaratne and Hemingway, 2000). Recent work on Aedes carboxylesterases also confirms the sequestration role of mosquito esterases. However, as shown by western blot and immunolocalization studies, these esterases which are responsible for temephos resistance in Ae. aegypti and Ae. albopictus are expressed at higher levels primarily in malpighian tubules and nerve tissues (Grigoraki et al., 2016).

\section{Glutathione S-transferases}

Glutathione S-transferases (GSTs) are dimeric multifunctional enzymes involved in detoxification of a large range of xenobiotics. These enzymes catalyze the nucleophilic attack of reduced glutathione (GSH) on the electrophilic centers of lipophilic compounds. Elevated GST activity has been associated with resistance to different classes of insecticides. In mosquitoes, the metabolic resistance based on GSTs is the major mechanism of DDT resistance (Hemingway and Ranson, 2000). At least six classes of GSTs have been recognized in mosquitoes according to the Greek letter based nomenclature adopted in line with the mammalian system (Chelvanayagam et al., 2001). Resistance to insecticides can be provided by GSTs through several different pathways: O-dealkylation or O-dearylation conjugation for organophosphates, dehydrochlorination and GSH conjugation for organochlorines, detoxification of lipid peroxidation products and passive sequestration for pyrethroids (CheMendoza et al., 2009). GSTs also contribute to reduce oxidative stress induced by insecticides (Ding et al., 2005). The epsilon class and the delta class have been reported to be involved in resistance towards various insecticides (Ortelli et al., 2003). Molecular mechanisms responsible for elevated GST activity in mosquitoes are mostly due to regulatory changes that increase its transcriptional rate, although mRNA stability and gene amplification are also found in other insects (Hemingway et al., 2004; Vontas et al., 2002). In Ae. aegypti, the actual GST-based resistance mechanism is probably caused by a trans-acting regulator. The resistance mutation is thought to disrupt the transacting repressor preventing the normal function of the repressor leading to elevated levels of enzyme in resistant mosquitoes. Therefore, DDT resistant An. gambiae are characterized by having higher mRNA levels than susceptible counterparts (Ranson et al., 2001). Upregulation of GST gene GSTE2 has been reported from resistant mosquito species (Ranson and Hemingway, 2005). In the mosquito, An. gambiae, increased expression of an epsilon class GST (GSTE) confers resistance to DDT and epiphyllocoumarin has been shown to inactivate this enzyme both in a time-dependent and a concentration-dependent manner when expressed in Escherichia coli cells. It has been suggested that this can be used to knock down GSTs when used in combination with DDT in malaria control programmes where DDT resistance is mediated by GSTs (Marimo et al., 2016).

\section{Monooxygenases}

Monooxygenases which are also known as oxidases or cytochrome $\mathrm{P}^{450} \mathrm{~s}$, are a complex family of enzymes. They bind to molecular oxygen and receive electrons from
NADPH to introduce an oxygen molecule in to the substrate. $\mathrm{P}^{450}$ monooxygenases are involved in the metabolism of virtually all insecticides. Increased $\mathrm{P}^{450}$ gene expression is known to result in increased levels of total $\mathrm{P}^{450} \mathrm{~s}$ and thereby responsible for insecticide resistance (Gong et al., 2013). Monooxygenases are also responsible for the activation of organophosphorus molecules i.e. organophosphates are applied as thionates because of their ability to penetrate the insect cuticle fast, and monooxygenases convert the thionate analogues to highly toxic oxon analogues inside the mosquito body (Karunaratne, 1998).

In vector mosquitoes pyrethroid resistance is associated with increased monooxygenase activity (Brogdon et al., 1997; Gong et al., 2013). Nomenclature of the $\mathrm{P}^{450}$ super family is based on amino acid sequence homologies, with all families having the CYP prefix followed by a numeral for the family, a letter for the sub family, and a numeral for the individual gene. Insect $\mathrm{P}^{450} \mathrm{~S}$ have been assigned to six families: five are insect-specific and one, CYP4, has sequence homologies with families in other organisms (Hemingway and Ranson, 2000). Members of the mosquito CYP6Z subfamily such as Ae. aegypti CYP6Z8 and its An. gambiae orthologue CYP6Z2, have been frequently associated with pyrethroid resistance. However, their role in the pyrethroid degradation pathway remains unclear. Using a genetically modified yeast strain to overexpress $A e$. aegypti cytochrome $\mathrm{P}^{450}$ reductase and CYP6Z8, it has been shown that CYP6Z8 metabolizes common pyrethroid metabolites produced by carboxylesterases, and the CYP6Z8 transcription is induced by these metabolites. Three genes namely CYPM2, CYP6P3 and CYPZ2 are responsible for pyrethroid resistant in An. gambiae (Muller et al., 2007; McLaughlin et al., 2008; Djouaka et al., 2007). An. gambiae CYP6Z2 behaves in the same way and it is expected that other mosquito CYP6Zs also have a similar role in pyrethroid degradation (Chandor-Proust et al., 2013). CYP6P9a and CYP6P9b genes are highly overexpressed in permethrin-resistant $A n$. funestus mosquitoes conferring resistance to both type I and II pyrethroids (Riveron et al., 2013).

\section{Target site insensitivity through alteration of target sites}

Insects acquire target site insensitivity mainly through nonsilent point mutations within structural genes. However, only a limited number of changes can decrease insecticide sensitivity without disrupting the normal physiological functions of the target site (Karunaratne, 1998; Hemingway et al., 2004). Therefore, the number of possible amino acid substitutions is very limited. Hence, identical resistanceassociated mutations are commonly found across highly diverged taxa. The classic leucine to phenylalanine mutation of voltage-gated sodium channel proteins, the target site of DDT and pyrethroids, is found in An. subpictus from Sri Lanka (Karunaratne et al., 2007) which is similar to that of African An. gambiae s.s. (Martinez-Torres et al., 1998) indicating an independent origin of the same mutation in two different species which are geographically isolated. Mutations in target sites alter its binding affinities to different insecticides depending on the molecular structure 
of the insecticide (O'Reilly et al., 2006). Therefore, altered target sites do not mediate the same level of resistance to all the insecticides belong to a particular group. The degree to which the normal physiological function is impaired by the resistance mutation is reflected in the fitness of resistant individuals in the absence of insecticide selection. Fitness cost has important implications for the persistence of resistance in the field. Since the primary function of the enzyme is not disrupted, an increased production of an enzyme in the metabolic resistance may have a lower associated fitness cost than an alterations in the structural gene.

\section{Insensitive acetylcholinesterases}

Organophosphate and carbamate target site acetylcholinesterases (AChEs) is the enzyme, which hydrolyzes the excitatory neurotransmitter acetylcholine on the post-synaptic nerve membrane. Insect AChE has a substrate specificity intermediate between vertebrate $\mathrm{AChE}$ and butyrylcholinesterase. Inhibition of acetylcholinesterases by the insecticides results in continuous stimulation of post-synaptic nerve membrane leading to the death of the insect. Alterations in AChE in resistant insects result in a decreased sensitivity to inhibition of the enzyme by these insecticides. Two forms of AChEs have been identified; a protein responsible for the synaptic transmission (AChE1) and a protein not involved in the nerve impulse transmission (AChE2). Sensitivity level of these two forms towards organophosphates and carbamates is different and the presence of these two proteins, synaptic and non-synaptic, can be identified using specified substrates and kinetic parameters (Houndete et al., 2010). The AChE1 and AChE2 are encoded by two genes ace-1 and ace-2 respectively (Strode et al., 2008). It has been reported that two mutations (G119S and F455W) from ace1 are responsible for insensitivity to $\mathrm{OP}$ and carbamates in mosquitoes (Liu, 2015). Using a PCR based diagnostic test, the presence of the G119S mutation in the ace-1 gene has been detected in An. albimanus from Peru (Liebman et al., 2015) and, in both An. coluzzii and An. gambiae from Ghana (Chabi et al., 2016).

\section{Insensitive $G A B A$ receptors}

Gama-amino butyric acid (GABA) is the major inhibitory neurotransmitter in mammals and insects. Cyclodines, a sub group of organochlorines, target GABA receptors which are hetero-multimeric gated chloride-ion channels in the insect's central nervous system and in neuromuscular junctions. These receptors are formed by the oligomerization of five subunits around a central transmitter-gated ion channel and four transmembrane domains (M1-M4) (Liu, 2015). Alanine-to-serine (A296S) mutation in the second transmembrane domain of the GABA receptor subunit, Rdl, was first identified in Drosophila and later found to be associated with target site insensitivity giving resistance to insecticides such as dieldrin and fipronil in insects including Ae. aegypti and An. gambiae (Thompson et al., 1993; Taylor-Wells et al., 2015). The only variation in resistant insects is that glycine rather than serine can sometimes be the substituted amino acid residue (ffrench-
Constant et al., 1998). Molecular cloning of Rdl cDNA from a strain of the malaria mosquito, An. gambiae, which is highly resistant to dieldrin revealed that A296G coexists with another mutation $\mathrm{T} 345 \mathrm{M}$ in the third transmembrane domain. Using Xenopus laevis oocytes expression system, it has been shown that the sensitivity to fipronil, deltamethrin and imidacloprid is reduced or abolished with A296G and $\mathrm{A} 296 \mathrm{G}+\mathrm{T} 345 \mathrm{M}$ mutations while T345M alone has no significant effect. It has been suggested that while T345M itself does not affect insecticide sensitivity, it may serve to offset the structural impact of A296G (Taylor-Wells et al., 2015). It appears that despite the wide spread switch away from the use of cyclodiene insecticides for agricultural and public health use, the resistance alleles are still found at relatively high frequencies in insect field populations.

\section{Insensitive sodium channel regulatory proteins}

DDT (and its analogues) and pyrethroids bind to sodium channel regulatory proteins of the insect nervous system causing persistent activation (opening) of the sodium channels by delaying the normal voltage-dependent mechanism of inactivation (closing). Persistent opening will hinder the active outside pumping of sodium ions leading to continuous firing of the nerves causing the ultimate coma and death of the insect. Insensitivity of the sodium channels to insecticide inhibition was first recorded in Musca domestica as a knock-down resistance- $k d r$ (Farnham and Sawicki, 1976). In mosquitoes, there have been many reports of suspected $k d r$-like resistance inferred from cross resistance between DDT and pyrethroids, which act on the same site within the sodium channel. These reports have been later validated by electrophysiological measurements in Ae. aegypti and An. stephensi (Karunaratne, 1998).

$k d r$ associated leucine to phenylalanine (L1014F) point mutation was first characterized from the S6 transmembrane segment of domain II of sodium channel sequence of $M$. domestica with 10-20 fold resistance to DDT and pyrethroids. A second methionine to threonine substitution (M918T) increased the resistance 500-fold in 'super-kdr' in houseflies (Williamson et al., 1996). To date, more than thirty unique resistance associated mutations or combination of mutations have been detected in pyrethroid and DDT resistant insect populations (Rinkevich et al., 2013). Presence of $k d r$ mutations of mosquito populations have been studied extensively (Singh et al., 2009; Kazanidou et al., 2009; Komagata et al., 2014; Thi et al., 2016; Saingamsook et al., 2017; Nugapola et al., 2017; Hegoda et al., 2017; Saavedra-Rodriguez et al., 2018). Variability in substitution at a single site such as $\mathrm{L} 1014 \mathrm{~F} / \mathrm{H} / \mathrm{S} / \mathrm{C} / \mathrm{W}$ resulting pyrethroids resistance can also be seen. This massive parallel and divergent evolution of resistance demonstrates not only are these sites critical for pyrethroids action, but also raises the possibility that the substitution of amino acids at these sites can potentially vary based on the type of pyrethroids used to select the resistant population (Rinkevich et al., 2013). Changes associated with pyrethroid/DDT resistance in the sodium channels of insects are more variable than those seen in the GABA receptors but still appear to be limited because of the constrains by the number of modifications that can 
influence pyrethroid/DDT binding to the sodium channels without disrupting the physiology. There is already a tendency to investigate pyrethroid-resistant insects with a PCR approach confined to regions where a $k d r$ mutation has already been detected. Hence the resistance-associated changes in other parts of the sodium-channel gene could be easily over looked (Hemingway and Ranson, 2000).

\section{Cuticular resistance (Reduced Penetration)}

Cuticular resistance is mediated by a thickening of or a change of chemical composition of insect cuticle to reduce penetration of insecticides into the insect body. Reduced penetration in turn can facilitate the action of metabolic enzymes by providing more time for detoxification as well. Cuticular resistance is considered to confer cross-resistance to multiple insecticides since most of the insecticides are lipophilic in nature (Scott, 1989; Nkya et al., 2013). In An. funestus mosquitoes pyrethroid resistance has been linked to cuticular thickening and the number of genes encoding for cuticle proteins are reported to be over expressed in resistance mosquitoes (Awolola et al., 2009; Wood et al., 2010; Gregory et al., 2011).

Increased expression of cytochrome $\mathrm{P}^{450}$ enzymes i.e. CYP4G16 and CYP4G17, which catalyzes epicuticular hydrocarbon biosynthesis, is associated with quantitative modification of cuticular hydrocarbons of highly pyrethroid resistant An. gambiae, An. arabiensis and Ae. aegypti populations. Overexpression of these enzymes increases cuticular hydrocarbon deposits in the epicuticle in resistant insects making it more resistant to insecticide intake. It has been proposed that the cuticular resistance as observed by reduced rate of ${ }^{14} \mathrm{C}$ deltamethrin penetration in these mosquitoes is governed by increased expression of cytochrome $\mathrm{P}^{450}$ monooxygenases (Komagata et al., 2014; Balabanidou et al., 2016; Bass and Jones, 2016).

\section{MONITORING INSECTICIDE RESISTANCE AND UNDERLYING MECHANISMS}

\section{Detection of resistance status of a population}

Resistance status of a mosquito population can be assessed by conducting adult or larval bioassays according to WHO guidelines (WHO, 2016d). Larval bioassays are conducted by immersing larvae in dechlorinated water with known insecticide concentrations. Adults are exposed to insecticides by tarsal contact method where the mosquitoes are allowed to rest on insecticide impregnated Whatman No. 1 filter papers in WHO tool kit chambers. Actual mortalities can be adjusted with control mortalities by using Abbotts formula (only if the control mortalities are $<20 \%$ ) (Matsumara, 1985). Percentage mortalities (probability Y axis) can be plotted against the log dosage/concentration of the insecticide to obtain Log-probit mortality curves. The lethal dosage or the lethal concentration which kills $50 \%$ $\left(\mathrm{LD}_{50}\right.$ or $\left.\mathrm{LC}_{50}\right)$ or $90 \%\left(\mathrm{LD}_{90}\right.$ or $\left.\mathrm{LC}_{90}\right)$ of the population can be calculated from these curves. Instead of mortality, knock-down rates are used to obtain KT values, especially for pyrethroids (Karunaratne, 1999). Instead of dosage/ concentration, time can be used as the variable to obtain $\mathrm{LT}_{50}$ or $\mathrm{LT}_{90}$ values (Karunaratne et al., 2007). Mortality curves can be compared between the populations and also with a susceptible population to assess the resistance status. Resistance ratio of population is calculated by comparing its LD values with that of a susceptible strain. Log-probit mortality curve of a population shifts along the $\mathrm{X}$-axis during the resistance development indicating that higher dosages are needed to kill the population. When the population has a heterogeneous response to a particular insecticide, the mortality curve cannot be fitted into a regression line. A characteristic sigmoid shape mortality curve represents susceptible homozygous (SS), heterozygous (RS) and resistant homozygous (RR) proportions of the population (Bandara and Karunaratne, 2017). WHO susceptible tests with discriminative dosages are used to obtain the resistance percentages (percentage of survivals) of a population. Depending on the survival rate, the population response can be classified as susceptible (> 98\% mortality), possibly resistant $(80-97 \%$ mortality) or resistant $(<80 \%$ mortality) for a particular insecticide (WHO, 2016d).

\section{Detection of underlying resistance mechanisms}

Synergistic bioassays are used to identify the presence of metabolic enzyme mediated insecticide resistance. Preexposure of mosquitoes to an enzyme inhibitor (synergist) will increase the mortality rates in bioassays if that particular enzyme is responsible for resistance. Piperonyl butoxide (PB) is commonly used as a monooxygenase inhibitor whereas DEF (S,S,S-tributyl phosphorothioate), TPP (triphenyl phosphate) and IBP (S-benzyl O.Odiisopropyl phosphorothionate) are used as esterase inhibitors. However, all the enzymes may not be equally susceptible to inhibition by these inhibitors. Therefore, the lack of synergism does not totally exclude the presence of a particular mechanism (Soderlund and Bloomquist, 1990).

Presence of metabolic enzyme mediated resistance can also be monitored by conducting biochemical assays using individual mosquito homogenates (WHO, 1998). Specific activities of esterases and GSTs of a mosquito can be calculated and the amount of monooxygenases (cytochrome $\mathrm{P}^{450} \mathrm{~s}$ ) is indirectly estimated by quantifying the amount of bound heam in the mosquito homogenate (Brogdon et al.,, 1997; WHO, 1998). Presence of elevated carboxylesterases can also be detected by native polyacrylamide gel electrophoresis (Native PAGE) (WHO, 1998). Gels can be stained in the presence of insecticides to assess their inhibition by insecticides (Karunaratne, 1999). Involvement of malathion carboxylesterases, a group of qualitatively changed esterases for higher malathion detoxification, in resistance can be assessed by incubating mosquito homogenates with malathion followed by testing for metabolic products (WHO 1998; Karunaratne and Hemingway, 2001). Apart from biochemical techniques, molecular biological techniques are also widely used to detect the involvement of metabolic enzymes in resistance. RFLPs have been used as a main technique in detecting carboxylesterase alleles in Culex pipiens mosquitoes (Zhang et al., 2012). Microarray and Quantitative real time PCR (qRT-PCR) have been applied to investigate the activity of monooxygenase levels of dengue vectors 
(Komagata et al., 2014). Other advance molecular based methods such as microsatellite genotyping to identify level of carboxylesterases in Ae. aegypti have improved the efficiency of monitoring resistance mechanisms (Paiva et al.,, 2016). Detoxification chips have been introduced to estimate differential expression of metabolic enzyme genes using microarray analysis of cDNA (David et al., 2005; Strode et al., 2008).

Sensitivity of the target site acetylcholinesterase can be estimated using biochemical assays. The percentage activity remaining in the insecticide inhibited fraction compared to the activity of uninhibited fraction is used to show the degree of sensitivity of acetylcholinesterases (WHO, 1998). PCR based techniques have been developed to determine the prevalence of mutations responsible for insensitive target sites in the field populations of mosquitoes. For instance, Allele Specific PCR (AS-PCR), Amplification Refractory Mutation System (ARMS) and Primer Introduced Restriction Analysis-PCR (PIRAPCR) methods have been developed for $k d r$ genotyping of An. culicifacies s.l. populations (Singh et al., 2009). Furthermore, insensitivity of Ace genes have been studied for malaria mosquitoes using PCR based methods such as, PCR-RFLP, TaqMan and digital droplet PCR (ddPCR) (Djogbénou et al., 2015). Presence of both $k d r$ mutations and AChE insensitivity in An. gambiae has been tested using multiplex PCR by Kazanidou et al (2009). Advanced molecular tools are increasingly becoming popular among researchers to enhance the accuracy and efficiency of experiments conducted to develop better vector control strategies.

\section{OTHER CONTRIBUTORY FACTORS}

Many major mosquito vectors of human diseases are anthropogenic in nature and show various adaptations to environmental changes (Ramasamy and Surendran, 2016). The vector control efforts have become more challenging due to their ability to explore and breed in diverse breeding habitats and rapid responses to changing environment. This phenotypic plasticity shown by different mosquito vectors to changing environmental conditions allow them to become resistant to insecticides.

Mosquito larvae derived from polluted water have shown more tolerance to insecticides than the larvae develop in non-polluted water (Fossog et al., 2012). In malaria vectors which exist as species complexes and are well known clean water breeders, the sibling species which act as major vectors have shown higher insecticide tolerance and ability to breed in polluted water i.e. sibling species E of An. culicifacies s.l. in Sri Lanka (Surendran et al., 2006; Gunatilaka and Karunaraj, 2015), An. coluzzi (M molecular form) of the Gambaie complex in Cameroon (Kamdem et al., 2012; Nwane et al., 2013). However it is not clear whether this resistance development is a result of their adaptation to breed in polluted water or vice versa.

Agrochemicals, allelochemicals from natural xenobiotics and pollutants originating from industry can mediate resistance mechanism development in mosquitoes (Nkya et al., 2013). Agrochemicals have made a higher selection pressure on resistance development than insecticides that are used for vector control in $A n$. arabiensis in Tanzania (Matowo et al., 2010). Various toxic compounds such as benzothiazole (Suwanchaichinda and Brattsten, 2002), polycyclic aromatic hydrocarbons (Riaz et al., 2009) are reported to increase tolerance of mosquitoes to insecticides. Although various studies indicate that environmental pollutants can affect mosquito detoxification systems and thus leading to better tolerance to insecticides, the impact of these pollutants on the inherited resistance remains unclear (Nkya et al., 2013). Xenobiotics of anthropogenic origin and present in mosquito breeding environment have shown to alter expression of genes encoding cuticular proteins associated with insecticide resistance (David et al., 2010). Studies have also shown that insect microbiota can also influence the development of insecticide resistance in insects (Kikuchi et al., 2012).

\section{RECENT APPROACHES AND CONCERNS}

Driving mechanisms for insecticide resistance in mosquitoes has been studied using genome-wide transcription and microarray analysis, quantitative RT-PCR, in-vitro expression systems and transgenic approaches. Expression of genes that confer resistance have been studied and the proteins have been characterized extensively. In vitro and in vivo functional studies have been carried out to confirm the involvement of overexpressed genes in the metabolic detoxification mechanisms. Such combined approaches have revealed that several genes are highly overexpressed in resistant mosquitoes (Hemingway, 1985; Grigoraki et al., 2016; Riveron et al., 2013; Strode et al., 2008). Microarray and transcriptome analysis have revealed the involvement of new candidate genes, which are involved in insecticide resistance of mosquitoes (David et al., 2005; Wang et al., 2015). Silencing of genes through RNA interference (RNAi) in insects has been a powerful tool to study mortality, growth and insecticide susceptibility in the recent past (Killiny et al., 2014). Partial silencing of one of the Epsilon glutathione transferases by RNAi resulted in an increased susceptibility to deltamethrin suggesting the involvement of GST in resistance to pyrethroid insecticides (Lumjuan et al., 2011). RNAi mediated knockdown of cytochrome $\mathrm{P}^{450}$ reductase (CPR) in An. gambiae increased sensitivity to permethrin (Lycett et al., 2006). Silico 3-D modeling and molecular docking studies have been used to understand substrate specificities of metabolic enzymes and their contribution to metabolic resistance (Schuler and Berenbaum, 2013).

With the availability of new technologies, researchers have undertaken genome-wide high-throughput analysis to provide new insight on the basic biological processes associated with insecticide resistance (ffrench-Constant, 2013). Discovery of multiple gene families, which are responsible for insecticide resistance in mosquitoes, and their interactions have created a much more complicated situation than it was thought to be earlier.

\section{MANAGING INSECTICIDE RESISTANCE}

Insecticides pollute the environment and their continuous application can cause insecticide resistance in insects. Once 
the resistance is developed in mosquitoes, it may exhibit cross-resistance to chemicals to which a particular insect population has never been exposed before. Besides, we need to manage the development of resistance in mosquito populations carefully as there are not many effective insecticides available in the market and the number of new chemicals to be introduced is also limited. Therefore, before implementing any chemical control measure against a particular insect population, a thorough analysis on the degree of damage and the threat to human life it causes, need to be assessed in order to justify that the chemical control is essential. A proper knowledge on different aspects of the target species such as behavior, abundance, prevalence, distribution patterns with the climatic factors, genetic diversity and population genetic structure etc. should be gathered in order to select effective insecticides and method of application, correct timing and frequency of application. Resistance status of the target population to different groups of insecticides and the underlying resistance mechanisms have to be evaluated to identify the most effective insecticide/ insecticide group and the correct dosage of application. Moreover, the most susceptible life cycle stage for the selected insecticide should be identified prior to the insecticide application. Integration of biological and physical controlling measures can also be introduced to maximize the controlling effect.

\section{CONCLUSION}

In order to delay the development of insecticide resistance, insecticide management tools such as rotations, mosaics, and mixtures have been proposed and mathematical models have been introduced to estimate their optimal use. However, practical difficulties in estimating changes in resistance gene frequencies in large samples of insects are a severe drawback in this process. Genomic diversity, differential upregulation and post-transcriptional editing of resistance conforming genes and different binding specificities, and the presence of different subspecies with varying vectorial capacities have imposed severe threats to vector control programmes today. However, with our ability to manipulate the insect genome and the availability of advanced molecular tools, new strategies will soon be available for the management of insecticide resistance for future vector control programs.

Competing interests: The authors declare that they have no competing interests.

\section{REFERENCES}

Awolola, T.S., Oduola, O.A., Strode, C., Koekemoer, L.L., Brooke, B. and Ranson, H. (2009). Evidence of multiple pyrethroids resistance mechanisms in the malaria vector Anopheles gambiae sensu stricto from Nigeria. Transaction of the Royal Socety of tropical Medicine and Hygenes 103:1139-1145.

Balabanidou, V., Kampouraki, A., MacLean, M., Blomquist, G.J., Tittiger, C., Juarez, M.P., Mijailovsky, S.J., Chalepakis, G., Anthousi, A., Lynd, A., Antoine, S., Hemingway J., Ranson, H., Lycett, G. and Vontas, J. (2016). Cytochrome P450 associated with insecticide resistance catalyzes cuticular hydrocarbon production in Anopheles gambiae. Proceedings of the National Academy of Science of USA 113(33):68-73.

Bandara, K. J. and Karunaratne, S.H.P.P. (2017). Mechanisms of acaricide resistance in the cattle tick Rhipicephalus (Boophilus) microplus in Sri Lanka. Pesticide biochemistry and physiology 139:6872.

Bang, Y.H. (1985). Implication in the control of malaria vectors with insecticides in tropical countries of Southeast Asia region. Part II. Consequences of insecticide use. Journal of Communicable Diseases 17: 300-310.

Bass, C. and Jones, C.M. (2016). Mosquitoes boost body armor to resist insecticide attack. Proceedings of the National Academy of Sciences 113(33):9145-9147.

Bradley, D.J. (1998). The particular and general issues of specificity and verticality in the history of malaria control. Parassitologia 40:5-10.

Brogdon, W.G., McAllister, J.C. and Vulule, J. (1997). Hemeperoxidase activity measured in single mosquitoes identifies individuals expressing the elevated oxidase mechanism for insecticide resistance. Journal of the American Mosquito Control Association 13:233-37.

Caraballo, H. and King, K. (2014). Emergency department management of mosquito-borne illness: Malaria, dengue, and West Nile Virus. Emergency Medicine Practice 16(5):1-23.

Center for Disease Control and Prevention (2016). Vectors of lymphatic filariasis.http://www.cdc.gov/parasites/ lymphaticfilariasis/gen_info/vectors.html, Accessed 4 Septemebr, 2016.

Chabi, J., Baidoo, P.K., Datsomor, A.K., Okyere, D., Ablorde, A., Iddrisu, A., Wilson, M.D., Dadzie, S.K., Jamet, H.P. and Diclaro, J.W. (2016). Insecticide susceptibility of natural populations of Anopheles coluzzii and Anopheles gambiae (sensustricto) from Okyereko irrigation site, Ghana, West Africa. Parasites and Vectors 9 (1):182-190.

Chandor-Proust, A., Bibby, J., Régent-Kloeckner, M., Roux, R., Guittard-Crilat, E., Poupardin, R., Riaz, M.A., Paine, M., Dauphin-Villemant, C., Reynaud, S. and David, J.P. (2013). The central role of mosquito cytochrome P450 CYP6Zs in insecticide detoxification revealed by functional expression and structural modeling. Biochemical Journal 455:75-85.

Chelvanayagam, G., Parker, M.W. and Board, P.G. (2001). Fly fishing for GSTs: a unified nomenclature for mammalian and insect glutathione S-transferses. Chemico-Biological Interactions 133:256-260.

Che-Mendoza, A., Penilla, R.P. and Rodriguez, A. (2009). Insecticide resistance and glutathione S-transferases in mosquitoes: A review. African Journal of Biotechnology 8(8): 1386-1397.

David, J.P., Strode, C., Vontas, J., Nikou, D., Vaughan, A., Pignatelli, P.M., Louis, C., Hemingway, J. and Ranson, H. (2005). The Anopheles gambiae detoxification chip: a highly specific microarray to study metabolic-based insecticide resistance in malaria vectors. Proceeding of National Academy of Science USA 102(11):4080-4084. 
David, J., Coissac, E., Melodelima, C., Poupardin, R., Riaz, M.A., Chandor-Proust, A. and Reynaud, S. (2010). Transcriptome response to pollutants and insecticides in the dengue vectors Aedes aegypti using next-generation sequencing technology. BMC Genomics 11(1):216-228.

Ding, Y., Hawkes, N., Meredith, J., Eggleston, P., Hemingway, J. and Ranson, H. (2005). Characterization of the promoters of Epsilon Glutathione transferases in the mosquito Anopheles gambiae and their response to oxidative stress. Biochemical Journal 387:879 -888.

Djogbénou, L. S., Assogba, B., Essandoh, J., Constant, E. A., Makoutodé, M., Akogbéto, M. and Weetman, D. (2015). Estimation of allele-specific Ace-1 duplication in insecticide-resistant Anopheles mosquitoes from West Africa. Malaria Journal 14(1):507-517.

Djouaka, R. F., Bakare, A. A., Bankole, H. S., Doannio, J. M., Coulibaly, O. N., Kossou, H. and Akogbeto, M. C. (2007). Does the spillage of petroleum products in Anopheles breeding sites have an impact on the pyrethroid resistance? Malaria Journal 6(1):159.

Farnham, A.W. and Sawicki, R.M. (1976). Development of resistance to pyrethroids in insects resistant to other insecticides. Pesticide Science 7:278-82.

ffrench-Constant, R.H. (2013). The molecular genetics of insecticide resistance. Genetics 194:807-815.

ffrench-Constant, R.H., Pittendrigh, B., Vaughan, A. and Anthony, N. (1998). Why are there so few resistanceassociated mutations in insecticide target genes? Philosophical Transactions of the Royal Society of London Ser B. 353:1685-93.

Fossog, B.T., Kopya, E., Ndo, C., Menze-Djantio, B., Costantini, C., Njiokou, F., Awono-Ambene, P. and Antonio-Nkondjio, C. (2012). Water quality and Anopheles larval tolerance to pyrethroids in the cities of Doula and Yaoundé (Cameroon). Journal of tropical medicine, article ID 42987.

Gong, Y., Li, T., Zhang, L., Gao, X. and Liu, N. (2013). Permethrin induction of multiple cytochrome P450 genes in insecticide resistant mosquitoes, Culex quinquefasciatus. International Journal of Biological Science 9(9):863-871.

Gregory, R., Darby, A.C., Irving, H., Coulibaly, M.B., Hughes, M., Koekemoer, L.L., Coetzee, M., Ranson, H., Hemimgway, J., Hall, N. and Wondji, C.S. (2011). A de novo expression profiling of Anopheles funestus, malaria vector in Africa using 454 pyrosequencing. PLoS One 6:e17418.

Grigoraki, L., Balabanidou, V., Meristoudis, C., Miridakis, A., Ranson, H., Swevers, L. and Vontas J. (2016). Functional and immunohistochemical characterization of CCEae3a, a carboxylesterase associated with temephos resistance in the major arbovirus vectors Aedes aegypti and Ae. albopictus. Insect Biochemistry and Molecular Biology 74:61-67.

Gullemaud, T., Makate, N., Raymond, M., Hirst, B. and Callaghan, A. (1997). Esterase gene amplification in Culex pipiens. Insect Molecular Biology 6:319-27.

Gunathilaka, N. and Karunaraj, P. (2015). Identification of sibling species status of Anopheles culicifacies breeding in polluted water bodies in Trincomalee district of Sri
Lanka. Malaria Journal 14(1):214-221.

Hegoda, W.K.D.L., Fernando, H.S.D. and De Silva, B.G.D.N.K. (2017). Detecting of knock down resistance (Kdr) F1534C allele in the dengue vector Aedes aegypti in peri-urban areas of Colombo South, Sri Lanka. Journal of Entomology and Zoology Studies 5(5):1926-1929.

Hemingway, J. (1985). Malathion carboxylesterase enzymes in Anopheles arabiensis from Sudan. Pesticide Biochemistry and Physiology 23:309-13.

Hemingway, J. and Karunaratne, S.H.P.P. (1998). Mosquito carboxylesterases: a review of the molecular biology and biochemistry of a major insecticide resistance mechanism. Medical and Veterinary Entomology 12: $1-12$.

Hemingway, J. and Ranson, H. (2000). Insecticide resistance in insect vectors of human disease. Annual Review of Entomology 45:371-391.

Hemingway, J., Hawkes, N.J., McCarrol, L. and Ranson, H. (2004). The molecular basis of insecticide resistance in mosquitoes. Insect Biochemistry and Molecular Biology 34:653-665.

Houndete, T.A., Fournier, D., Ketoh, G.K., Glitho, I.A., Nauen, R. and Marti, T. (2010). Biochemical determination of acetylcholinesterase genotypes conferring resistance to the organophosphate insecticide chlorpyriphos in filed populations of Bemisia tabaci from Benin, West Africa. Pesticide Biochemistry and Physiology 98:115-120.

Kamdem, C., Fossog, B. T., Simard, F., Etouna, J., Ndo, C., Kengne, P., Etoa, F.X., Awono-Ambene, P., Fontenille, D. and Antonio-Nkondjio, C. (2012). Anthropogenic habitat disturbance and ecological divergence between incipient species of the malaria mosquito Anopheles gambiae. PloS One, 7(6):e39453.

Karunaratne, S.H.P.P., Jayawardena, K.G.I., Hemingway, J. and, Ketterman, A.J. (1993). Characterization of a B-type esterase involved in insecticide resistance from the mosquito Culex quinquefasciatus. Biochemical Journal 294:575-579.

Karunaratne, S.H.P.P., Hemingway, J., Jayawardena, K.G.I., Dassanayaka, V. and Vaughan, A. (1995). Kinetic and molecular differences in the amplified and non-amplified esterases from insecticide resistant and susceptible Culex quinquefasciatus mosquitoes. Journal of Biological Chemistry 270(52):31124-31128.

Karunaratne, S.H.P.P. (1998). Insecticide resistance in insects. Ceylon Journal of Science (Biological Sciences) 25:72-99.

Karunaratne, S.H.P.P., Vaughan, A., Paton, M.G., and Hemingway, J. (1998). Amplification of a serine esterase gene is involved in insecticide resistance in Sri Lankan Culex tritaeniorhynchus. Insect Molecular Biology 74:307-315.

Karunaratne, S. H.P.P. (1999). Insecticide cross-resistance spectra and underlying resistance mechanisms of Sri Lankan anopheline vectors of malaria. Southeast Asian Journal of Tropical Medicine and Public Health. 30(3): 460-469

Karunaratne, S.H.P.P. and Hemingway, J. (2000). Insecticide resistance spectra and resistance 
mechanisms in populations of Japanese encephalitis vector mosquitoes, Culex tritaeniorhynchus and Cx. gelidus, in Sri Lanka. Medical and Veterinary Entomology 14(4):430-6.

Karunaratne, S. H.P.P. and Hemingway, J. (2001). Malathion resistance and prevalence of the malathion carboxylesterase mechanism in populations of mosquito vectors of disease in Sri Lanka. Bulletin of the World Health Organization 79:1060-1064.

Karunaratne, S.H.P.P, Hawkes, N.J., Perera, M.D.B., Ranson, H. and Hemingway, J. (2007). Mutated sodium channel genes and elevated monooxygenases are found in pyrethroid resistant populations of Sri Lankan malaria vectors. Pesticide Biochemistry and Physiology 99:108-113.

Kazanidou, A., Nikou, D., Grigoriou, M., Vontas, J. and Skavdis, G. (2009). A Multiplex PCR Assay for Simultaneous Genotyping of kdr and ace-1 Loci in Anopheles gambiae. The American Journal of Tropical Medicine and Hygiene 80(2):236 - 238.

Kikuchi, Y., Hayatsu, M., Hosokawa, T., Nagayama, A. and Tago, K. (2012). Symbiont-mediated insecticide resistance. Proceeding of National Academy of Science USA 109 (22):8618-8622.

Killiny, N., Hajeri, S., Tiwari, S., Gowda, S. and Stelinski, L.L. (2014). Double-stranded RNA uptake through topical application mediates silencing of five CYP4 genes and suppresses insecticide resistance in Diaphorina citri. PLoS One 9(10):e110536. doi:10.1371/journal.pone.0110536.

Komagata, O., Itokawa, K., Shono, T., Ching Ng, L., Kobayashi, M. and Tomita, T. (2014). Mechanisms of Pyrethroid Resistance in the Dengue Mosquito Vector, Aedes aegypti: Target Site Insensitivity, Penetration, and Metabolism. PLoS Neglected Tropical Diseases 8(6):2948-2973

Lazear, H.M., Stringer, E.M. and de Silva, A.M. (2016). The emerging Zika virus epidemic in the Americas. Journal of American Medical Association 315(18): 1945-1946.

Liebman, K.A., Pinto, J., Valle J., Palomino, M., Vizcaino, L., Brogdon, W. and Lenhart,A. (2015). Novel mutations on the ace-1 gene of the malaria vector Anopheles albimanus provide evidence for balancing selection in an area of high insecticide resistance in Peru. Malaria Journal 14:74-84.

Liu, N. (2015). Insecticide resistance in mosquitoes: Impact, mechanisms, and research directions. Annual Review of Entomology 60:537-559.

Li, X., Schuler, M.A. and Berenbaum, M.R. (2007). Molecular mechanisms of metabolic resistance to synthetic and natural xenobiotics. Annual Review of Entomology 52:231-253.

Lumjuan, N., Rajatilekac, S., Changsoma, D., Wicheera, J., Leelapata, P., Prapanthadaraa, L., Somboonb, P., Lycettc, G. and Ranson, H. (2011). The role of the Aedes aegypti Epsilon glutathione transferases in conferring resistance to DDT and pyrethroid insecticides. Insect Biochemistry and Molecular Biology 41:203-209.

Lycett, G.J., McLaughlin, L.A., Ranson, H., Hemingway, J., Kafatos, F.C., Loukeris, T.G. and Paine, M.J. (2006).
Anopheles gambiae $\mathrm{P} 450$ reductase is highly expressed in oenocytes and in vivo knockdown increases permethrin susceptibility. Insect Molecular Biology 15(3):321-7.

Marimo, P., Hayeshi, R. and Mukanganyama, S. (2016). Inactivation of Anopheles gambiae Glutathione Transferase 2 by epiphyllocoumarin. Biochemisty Research International 2016. Article ID 2516092, http://dx.doi.org/10.1155/2016/2516092.

Martinez-Torres, D., Chandre, F., Williamson, M.S., Darriet, F., Berge, J.B., Devonshire, A.L., Guillet, P., Pasteur, N. and Pauron, D. (1998). Molecular characterization of pyrethroid knockdown resistance $(k d r)$ in the major malaria vector Anopheles gambiae s.s. Insect Molecular Biology 7:179-184.

Matowo, J., Kulkarni, M.A., Mosha, F.W., Oxborough, R.M., Kitau, J.A., Tenu, F. and Rowland, M. (2010). Biochemical basis of permethrin resistance in Anopheles arabiensis from Lowe Moshi, north-eastern Tanzania. Malaria Journal 9(1):193-202.

Matsumura, F. (1985) Toxicology of Insecticides. 2nd Edition, Plenum, New York.

McCarroll, L., Paton, M.G., Karunaratne, S.H.P.P., Jayasuriya, H.T.R., Kalpage, K.S.P. and Hemingway J. (2000). Insecticides and mosquito-borne diseases: Insecticide resistance in mosquitoes can also interfere with developing parasites. Nature 407:961-962.

McLaughlin, L.A., Niazi, U., Bibby, J., David, J.P., Vontas, J., Hemingway, J., Ranson, H., Sutcliffe, M.J. and Paine, M.J. (2008). Characterization of inhibitors and substrates of Anopheles gambiae CYP6Z2. Insect Molecular Biology 17(2):125-135.

Muller, P., Donnelly, M.J. and Ranson, H. (2007). Transcription profiling of a recently colonized pyrethroid resistant Anopheles gambiae strain from Ghana. BMC Genomics 8(1):36-48.

Nugapola, N.W.N.P., De Silva, W.A.P.P and Karunaratne, S.H.P.P. (2017). Presence of KDR type mutations in Pyrethroid and DDT resistant dengue mosquitoes Aedes aegypti and Aedes albopictus. Proceedings of the National Conference on Insect Vector Biology, Department of Zoology, University of Jaffna, Sri Lanka 18-19.

Naqqash, M.N., Gokce, A., Bakhsh, A. and Salim, M. (2016). Insecticide resistance and its molecular basis in urban insect pests. Parasitological Research 115:13631373.

Nkya, T.E., Akhouayri, I., Kisinza, W. and David, J. (2013). Impact of environment on mosquito response to pyrethroid insecticide: Facts, evidence and prospects. Insect Biochemistry and Molecular Biology 43:407416.

Nwane, P., Etang, J., Chouaibou, M., Toto, J.C., Koffi, A., Mimpfoundi, R. and Simard, F. (2013). Multiple insecticide resistance mechanism in Anopheles gambiae s.1. populations from Cameroon, Central Africa. Parasites and Vectors 6(1):41-55.

O’Reilly, A.O., Khambay, B.P.S., Williamson, M.S., Field, L.M., Wallace, B.A., and Davies, T.G.E. (2006). Modeling insecticide binding sites in the voltage-gated sodium channel. Biochemical Journal 396:255-263. 
Ortelli, F., Rossiter, L.C., Vontas, J., Ranson, H. and Hemingway, J. (2003). Heterologous expression of four glutathione transferase genes genetically linked to a major insecticide-resistance locus from the malaria vector Anopheles gambiae. Biochemical Journal 373: 957- 963.

Paiva, M. H., Lovin, D. D., Mori, A., Melo-Santos, M. A., Severson, D. W. and Ayres, C. F. (2016). Identification of a major Quantitative Trait Locus determining resistance to the organophosphate temephos in the dengue vector mosquito Aedes aegypti. Genomics 107(1):40-48.

Paton, M.G., Karunaratne, S.H.P.P., Giakoumaki, E., Roberts, N. and Hemingway, J. (2000). Quantitative analysis of gene amplification in insecticide resistant Culex mosquitoes. Biochemistry Journal 346:17-24.

Ramasamy, R. and Surendran, S.N. (2016). Mosquito vectors developing in atypical anthropogenic habitats - global overview of recent observations, mechanisms and impact on disease transmission. Journal of Vector Borne Diseases 53:91-98.

Ranson, H., Rossiter, L., Ortelli, F., Jensen, B., Wang, X., Roth, C.W., Collins, F.H. and Hemingway, J. (2001). Identification of a novel class of insect glutathione S-transferases involved in resistance to DDT in the malaria vector Anopheles gambiae. Biochemical Journal 359:259-304.

Ranson, H. and Hemingway, J. (2005). Mosquito glutathione transverses Methods. Enzymology 401: 226-241.

Reddy, M. R., Overgaard, H.J., Abaga, S., Reddy, V.P., Caccone, A., Kiszewski, A.E. and Slotman, M.A. (2011). Outdoor host seeking behaviour of Anopheles gambiae mosquitoes following initiation of malaria vector control on Bioko Island, Equatorial Guinea. Malaria journal 10(1): 184-194.

Rinkevich, F.D., Du, Y. and Dong, K. (2013). Diversity and convergence of sodium channel mutations involved in resistance to pyrethroids. Pesticide Biochemistry and Physiology 106:93-100.

Riveron, J.M.1., Irving, H., Ndula, M., Barnes, K.G., Ibrahim, S.S., Paine, M.J. and Wondji, C.S. (2013). Directionally selected cytochrome P450 alleles are driving the spread of pyrethroid resistance in the major malaria vector Anopheles funestus. Proceedings of the National Academy of Science USA 110(1):252-7.

Riaz, M. A., Poupardin, R., Reynaud, S., Strode, C., Ranson, H. and David, J. P. (2009). Impact of glyphosate and benzo (a) pyrene on the tolerance of mosquito larvae to chemical insecticides. Role of detoxification genes in response to xenobiotics. Aquatic Toxicology 93(1): 61-69.

Saavedra-Rodriguez, K., Maloof, F.V., Campbell, C.L., Garcia-Rejon, J., Lenhart, A., Penilla, P., Rodriguez, A., Sandoval, A.A., Flores, A.E., Ponce, G., Lozano, S. and Black IV, W.C. (2018). Parallel evolution of $v g s c$ mutations at domains IS6, IIS6 and IIIS6 in pyrethroid resistant Aedes aegypti from Mexico. Scientific Reports 8: 6747-6756.

Saingamsook, J., Saeung, A., Yanola, J., Lumjuan, N., Walton, C and Somboon, P. (2017). A multiplex PCR for detection of knockdown resistance mutations,
V1016G and F1534C, in pyrethroid-resistant Aedes aegypti. Parasites and Vectors 10(1):465-474.

Schuler, M.A. and Berenbaum, M.R. (2013). Structure and function of cytochrome P450S in insect adaptation to natural and synthetic toxins: Insights gained from molecular modeling. Journal of Chemical Ecology 39: 1232-1245.

Scott, J. G. (1989). Cross-resistance to the biological insecticide abamectin in pyrethroid-resistant house flies. Pesticide Biochemistry and Physiology, 34(1): 27-31.

Singh, O.P., Bali, P., Hemingway, J., Subbarao, S.K., Dash, A.P. and Adak, T. (2009). PCR-based methods for the detection of L1014 kdr mutation in Anopheles culicifacies s.1. Malaria Journal 8(1):154-162.

Soderlund, D. M., and J. R. Bloomquist. (1990). Molecular mechanisms if insecticide resistance, pp. 58-96. In R. T. Roush and B. E. Tabasnik (eds.), Pesticide resistance in arthropods. Chapman \& Hall, New York.

Strode, C., Wondji, C.S., David, J.P., Hawkes, N.J., Lumjuan, N., Nelson, D.R., Drane, D.R., Karunaratne, S.P., Hemingway, J., Black IV, W.C. and Ranson, H. (2008). Genomic analysis of detoxification genes in the mosquito Aedes aegypti. Insect Biochemistry and Molecular Biology 38:113-123.

Surendran, S. N., Ramasamy, M. S., De Silva, B. G. D. N. K. and Ramasamy, R. (2006). Anopheles culicifacies sibling species B and E in Sri Lanka differ in longevity and in their susceptibility to malaria parasite infection and common insecticides. Medical and veterinary entomology 20(1):153-156.

Suwanchaichinda, C. and Brattsten, L.B. (2002). Induction of miscrosomal cytochrome $\mathrm{P} 450 \mathrm{~s}$ by tire-leachte compounds, habitat components of Aedes albopictus mosquito larvae. Arch. Insect Biochemistry and Physiology 49:71-79.

Taylor-Wells, J., Brooke, B.D., Bermudez, I. and Jones, A.K. (2015). Two point mutations in the Anopheles gambiae Rdl GABA receptor reduce sensitivity to the antagonistic actions of fipronil, imidacloprid and deltamethrin. Journal of Neurochemistry 135:705-713.

Thi, K.P., Viet, H.H. and Nguyen, H.M. (2016). Major resistant mechanism to insecticides of Aedes aegypti mosquito: a Vector of dengue and Zika virus in Vietnam. Tropical Medicine Journal 1(2):1010-1016.

Thompson, M., Shotkoski, F. and Ffrench-Constant, R.H. (1993). Cloning and sequencing of the cyclodine insecticide resistant gene from the yellow fever mosquito Aedes aegypti. FEBS Letters 325:187-190.

Vontas, J., Small, G.J., Nikou, D.C., Ranson, H. and Hemingway, J. (2002). Purification, molecular cloning and heterologous expression of a glutathione S-transferase involved in insecticide resistance from the rice brown planthopper Nilaparvata lugens. Biochemlical Journal 362:329-337.

Wang, W., Liu, S.L., Liu, Y.Y., Qiao, C.L., Chen, S.L. and Cui F. (2015). Over-transcription of genes in a parathionresistant strain of mosquito Culex quinquefaciatus. Insect Science 22(1):150-156.

Weaver, S.C. and Reisen, W.K. (2010). Present and future arboviral threats. Antiviral Research 8, 328-345. 
Williamson, M.S., Martinez-Torres, D., Hick, C.A. and Devonshire, A.L. (1996). Identification of mutations in the housefly para-type sodium channel gene associated with knockdown resistance (kdr) to pyrethroids insecticides. Molecular Genetics and Genomics 252: 51-60.

Wood, O., Hanrahan, S., Coetzee, M., Koekemoer, L. and Brooke, B. (2010). Cuticle thickening associated with pyrethroid resistance in the major malaria vector Anopheles funestus. Parasites and Vectors 3(1): 67-74.

World Health Organization. (1998). Techniques to detect insecticide resistance mechanisms (field and laboratory manual). Geneva, Switzerland.

World Health Organization (WHO). (2012). Global Plan for insecticide resistance management in malaria vectors; Geneva, Switzerland.

World Health Organization (2016a). Malaria Fact Sheet: World Malaria Report 2015 http://www.who. $\mathrm{int} / \mathrm{malaria} / \mathrm{media} /$ world-malaria-report-2015/en/. Accessed 18 July 2016.

World Health Organization. (2016b). Fact sheet; Lymphatic filariasis. Available at http://www.who.int/mediacentre/ factsheets/fs102/en/, Accessed 22 Feb 2016.

World Health Organization. (2016c). Fact sheet; Dengue and severe dengue. Available at http://www.who.int/ mediacentre/factsheets/fs117/en/. Accessed 20 Feb 2016.
World Health Organization (2016d). Test procedures for insecticide resistance monitoring in malaria vector mosquitoes. Geneva, Switzerland.

Zhang, H., Meng, F., Qiao, C. and Cui, F. (2012). Identification of resistant carboxylesterase alleles in Culex pipiens complex via PCR-RFLP. Parasites \& Vectors 5(1):209-216.

Zhu, F., Lavine, L., O’Neal, S., Lavine, M., Foss, C. and Walsh, D. (2016). Insecticide resistance and management strategies in urban ecosystems. Insects 7(1):2-28.

Ziegler, R., Whyard,S., Downe, A.E.R., Wyatt, G.R. and Walker, V.K. (1987). General esterase, malathion carboxylesterase, and malathion resistance in Culex tarsalis. Pesticide Biochemistry and Physiology 8: 27985. 